\title{
GAMBARAN KORBAN MENINGGAL DENGAN CEDERA KEPALA PADA KECELAKAAN LALU LINTAS DI BAGIAN FORENSIK BLU RSUP PROF. Dr. R. D. KANDOU MANADO PERIODE TAHUN 2011- 2012
}

\author{
Feibyg Theresia Lumandung \\ James F. Siwu \\ Johannis F. Mallo \\ Bagian Ilmu Kedokteran Forensik dan Medikolegal Fakultas Kedokteran \\ Universitas Sam Ratulangi Manado \\ Email: feibygtheresialumandung@yahoo.com
}

\begin{abstract}
Abstrack: Traffic accidents lately occur anywhere and are already familiar. Most accidents are motor accident with head injury, where it can lead to death. This research isto describe the victim died with a head injury in a traffic accident forensics section BLU Prof.Dr.R.D.Kandou Hospital Manado period 2011-2012. In this study, researcher uses retrospective descriptive method. Datawere collected from medical records of all cases of accidents in the years 20112012. The conclusion ofthis research, cases of traffic accidents with head injuries are more prevalent than others, most especially in the region of the temporal head injury can effect to death. Researcher suggests that tightened regulations in traffic and further enhanced prevention efforts from the government, police, and medical teams.
\end{abstract}

Keyword : head injury, traffic accident

\begin{abstract}
Abstrak: Kecelakaan lalu lintas akhir-akhir ini terjadi dimana saja dan sudah tidak asing lagi. Kasus kecelakaan terbanyak adalah kecelakaan bermotor dengan cedera kepala, dimana hal ini dapat mengakibatkan kematian. Penelitian ini untuk mengetahui gambaran korban meninggal dengan cedera kepala pada kecelakaan lalu lintas dibagian forensik BLU RSUP Prof.Dr.R.D.Kandou Manado periode tahun 2011-2012. Dalam penelitian ini peniliti, menggunakan metode deskriptif retrospektif. Data penelitian dikumpulkan dari rekam medik seluruh kasus kecelakaan di tahun 2011-2012.Kesimpulan dari penelitian ini, kasus kecelakaan lalu lintas dengan cedera kepala lebih banyak terjadi dari cedera lainnya, khusunya paling banyak cedera kepala di regio temporalis yang dapat mengakibatkan kematian. Peneliti menyarankan agar lebih diperketat lagi peraturan-peraturan dalam berlalu lintas dan lebih ditingkatkan lagi berbagai usaha pencegahan dari pihak pemerintah, kepolisian, dan tim medis.
\end{abstract}

Kata kunci :Cedera kepala, kecelakaan lalu lintas.

Di era globalisasi saat ini perkembangan dan pertumbuhan jumlah kendaraan semakin meningkat pesat.Hal ini menimbulkan banyak masalah baik di lingkungan seperti bising kendaraan bermotor dan polusi udara, serta dapat menimbulkan kemacetan dan kecelakaan lalu lintas.Kecelakaan lalu lintas adalah setiap kecelakaan kendaraan bermotor yang terjadi di jalan raya.Kasus terbanyak dari kecelakaan lalu lintas saat ini adalah kecelakaan kendaraan bermotor dengan cedera kepala dengan jumlah prevalensi hingga 50,1\%. ${ }^{1}$ Cedera kepala adalah trauma kepala yang paling sering melanda dunia bagaikan wabah dalam kehidupan modern penggunaan kendaraan.Korban kecelakaan sepeda motor sebagian besar antara umur 21-30 tahun yang tercatat mencapai $43.5 \%{ }^{1}$ 
Menurut World Health Organization tahun (WHO) tahun 2004, Case Rate (CFR) cedera akibat kecelakaan lalu lintas tertinggi di jumpai di beberapa Negara Amerika Latin $(41,7 \%)$, Korea Selatan $(21,9 \%) .^{2}$ Dari seluruh kecelakaan yang ada WHO mencatat bahwa, 90\% kecelakaan lalu lintas dengan cedera kepala banyak terjadi di negara berkembang seperti Indonesia.Kecelakaan lalu lintas dengan cedera kepala penting diketahui, karena kecelakaan lalu lintas dapat mengakibatkan kematian serta kerugian lainnya. Tercatat di data kepolisian Republik Indonesia tahun 2011 mencapai 108.696 jumlah kecelakaan dengan 31.195 korban meninggal dan 35.285 mengalami luka berat, dan 55,1\% dari data tersebut mengalami cedera kepala, sedangkan kerugian lainnya seperti kerugian material mencapai Rp286.099.076.289. ${ }^{3}$

Korban kecelakaan ditinjau dari umur kebanyakan berada di rentang umur 21-30 tahun dengan pengendara dalam keadaan mabuk, dengan presentase laki-laki lebih banyak dari perempuan. ${ }^{1}$ Dokter di bidang kedokteran forensik dan dokter umum sewaktu-waktu dapat diminta dalam membuat Visium et Repertum bahkan autopsi dalam korban kecelakaan.

Adapun tujuan dalam penelitian ini adalah memberikan gambaran kepada masyarakat untuk mengetahui lebih spesifik tentang cedera kepala pada kecelakaan lalu lintas, membuka mata pemerintah agar lebih memperhatikan keadaan lalu lintas yang ada di Manado.

Kadiyali (1975), kecelakaan adalah tabrakan, overtuning atau slip yang terjadi di jalan terbuka pada lalu lintas umum yang menyebabkan luka, kematian/fatal, kerusakan pada kendaraan atau kerugian material. ${ }^{4}$ Penyebab kecelakaan lalu lintas antara lain adalah : manusia, sarana dan prasarana (kendaraan dan jalan), alam atau lingkungan. ${ }^{4}$

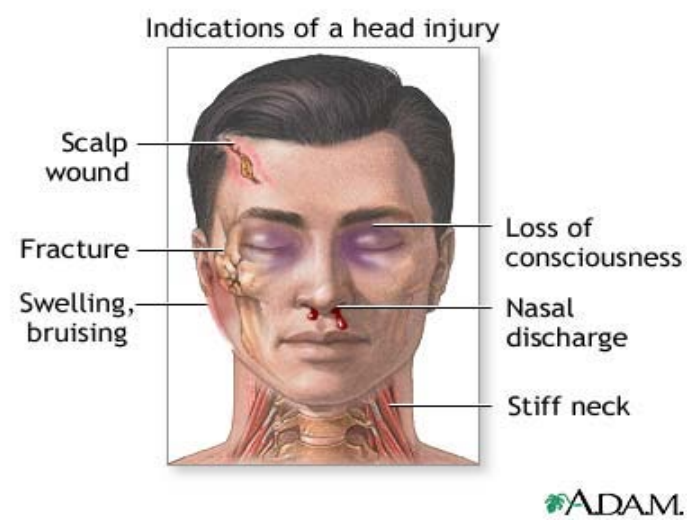

Gambar 1.Cedera kepala dari anterior ini memperlihatkan bahwa indikasi pada cedera kepala terdiri dari, luka Scalp, patah tulang, bengkak memar, hilangnya kesadaran, keluar darah dari hidung, dan kaku leher. Sumber: http://www.walgreens.com/marketing/library/contents.jsp

Kecelakaan terdiri dari kecelakaan lalu lintas,kecelakaan kerja, trauma pada olahraga, kejatuhan benda dan luka tembak. ${ }^{5}$

Penanganan awalterdiri dari Air way, breahting, circulation, danmenilai GCS. ${ }^{6}$

Penanganan juga dilakukan sesuai dengan berat ringannya cedera kepala serta dilakukan pada observasi saat di rumah sakit ataupun saat sudah pulang ke dari rumah sakit. ${ }^{7}$

Pencegahan pada dasarnya dilakukan untuk mengurangi peningkatan kasus kecelakaan yang berakibat trauma. Upaya pencegahan yang dilakukan yaitu: ${ }^{8}$

a. Pencegahan Primer

Pencegahan primer adalah pencegahan yang mencakup sebelum peristiwa terjadinya.Seperti pengatur lalu lintas, memakai sabuk pengaman dan memakai helm.

b. Pencegahan Sekunder

Pencegahan sekunder adalah pencegahan yang mencakup saat peristiwa terjadi yang dirancang untuk meminimalkan beratnya cedera yang terjadi.

c. Pencegahan Tertier 
Pencegahan tertier bertujuan untuk mengurangi terjadinya komplikasi yang lebih berat, penanganan yang tepat bagi penderita cedera kepala akibat kecelakaan lalu lintas, untuk mengurangi kecacatan dan memperpanjang harapan hidup.

Prognosis dari cedera kepala dilihat dari skor GCS yang penting dalam menentukan tingkat kesadaran dan berat ringannya cedera kepala. ${ }^{7}$

\section{METODE PENELITIAN}

Penelitian ini dilaksanakan di bagian Forensik BLU RSUP PROF.Dr.R.D.Kandou Manado pada bulan November-Desember 2013.Metode penulisan yang dilakukan adalah penelitian yang bersifat deskriptif retrospektif.Penelitian deskriptif retrospektif merupakan penelitian yang meninjau data-data pada masa lampau.Sampel yang digunakan pada penelitian ini adalah seluruh kasus meninggal yang berhubungan dengan kecelakaan lalu lintas yang ada di RSUP Prof.Dr.R.D.Kandou Manado tahun 2011-2012. Variabel penelitian yang akan diteliti terdiri dari jumlah kasus kecelakaan lalu lintas yang meninggal, jumlah kasus kecelakaan lalu lintas yang meninggal dengan cedera kepala, regio kepala yang mengalami cedera, jenis kelamin, umur, tingkat pendidikan, peran korban sebelum terjadi kecelakaan lalu lintas. Cara kerja yang dipakai pada penelitian ini terdiri dari, pengumpulan data secara retrospektif dari data yang ada di bagian Forensik BLU RSUP Prof.Dr.R.D.Kandou Manado tahun 2011-2012, dan pengolahan data dilakukan secara manual dan komputerisasi dan disajikan dalam bentuk tabel.

\section{HASIL PENELITIAN}

Tabel 1. Angka kematian akibat kecelakaan lalu lintas di Manado tahun 2011-2012 yang di periksa menurut data di bagian Forensik BLU RSUP Prof.Dr.R.D.Kandou.Manado

\begin{tabular}{lcccccc}
\hline \multicolumn{1}{c}{ Bulan } & Masuk & Periksa & Tidak periksa & Masuk & $\begin{array}{r}\text { Po12 } \\
\text { Periksa }\end{array}$ & $\begin{array}{c}\text { Tidak } \\
\text { Periksa }\end{array}$ \\
\hline Januari & 16 & 13 & 3 & 7 & 7 & 0 \\
Februari & 11 & 11 & 0 & 11 & 11 & 0 \\
Maret & 11 & 10 & 1 & 5 & 5 & 0 \\
April & 7 & 5 & 2 & 4 & 3 & 1 \\
Mei & 13 & 10 & 3 & 8 & 7 & 1 \\
Juni & 5 & 4 & 1 & 4 & 4 & 0 \\
Juli & 7 & 5 & 2 & 7 & 6 & 1 \\
Agustus & 6 & 6 & 0 & 5 & 5 & 0 \\
September & 14 & 10 & 4 & 10 & 10 & 0 \\
Oktober & 3 & 3 & 0 & 8 & 5 & 3 \\
November & 10 & 6 & 4 & 4 & 4 & 0 \\
Desember & 7 & 4 & 3 & 5 & 4 & 1 \\
Jumlah & 110 & 87 & 23 & 78 & 71 & 7 \\
Persentase & $100 \%$ & $79 \%$ & $21 \%$ & $100 \%$ & $91 \%$ & $9 \%$ \\
(\%) & & & & & & \\
\hline
\end{tabular}


Tabel 2. Angka kecelakaan lalu lintas yang meninggal dengan cedera kepala di Manado menurut data di bagian Forensik BLU RSUP.Prof.Dr.R.D.Kandou.Manado periode tahun 2011-2012

\begin{tabular}{lccccccccc}
\hline & \multicolumn{4}{c}{ Jumlah Kecelakaan } & \multicolumn{3}{c}{ Cedera Kepala } \\
\cline { 2 - 9 } \multicolumn{1}{c}{ Bulan } & \multicolumn{2}{c}{$\mathbf{2 0 1 1}$} & \multicolumn{2}{c}{$\mathbf{2 0 1 2}$} & \multicolumn{2}{c}{$\mathbf{2 0 1 1}$} & \multicolumn{2}{c}{$\mathbf{2 0 1 2}$} \\
\cline { 2 - 9 } & Periksa & $\begin{array}{c}\text { Tidak } \\
\text { periksa }\end{array}$ & Periksa & $\begin{array}{c}\text { Tidak } \\
\text { periksa }\end{array}$ & Ya & Bukan & Ya & Bukan \\
\hline Januari & 13 & 3 & 7 & 0 & 13 & 3 & 6 & 1 \\
Februari & 11 & 0 & 11 & 0 & 11 & 0 & 11 & 0 \\
Maret & 10 & 1 & 5 & 0 & 10 & 1 & 5 & 0 \\
April & 5 & 2 & 3 & 1 & 5 & 2 & 3 & 1 \\
Mei & 10 & 3 & 7 & 1 & 10 & 3 & 7 & 1 \\
Juni & 4 & 1 & 4 & 0 & 3 & 2 & 4 & 0 \\
Juli & 5 & 2 & 6 & 1 & 5 & 2 & 6 & 1 \\
Agustus & 6 & 0 & 5 & 0 & 6 & 0 & 5 & 0 \\
September & 10 & 4 & 10 & 0 & 8 & 6 & 10 & 0 \\
Oktober & 3 & 0 & 5 & 3 & 3 & 0 & 4 & 4 \\
November & 6 & 4 & 4 & 0 & 6 & 4 & 4 & 0 \\
Desember & 4 & 3 & 4 & 1 & 4 & 3 & 4 & 1 \\
Jumlah & 87 & 23 & 71 & 7 & 84 & 26 & 69 & 9 \\
Persentase & $79 \%$ & $21 \%$ & $91 \%$ & $9 \%$ & $76 \%$ & $24 \%$ & $88 \%$ & $12 \%$ \\
(\%) & & & & & & & & \\
\hline
\end{tabular}

Tabel 3. Jumlah kasus kecelakaan lalu lintas yang meninggal dengan cedera kepala sesuai regio kepala yang mengalami cedera pada data di bagian Forensik BLU RSUP Prof.Dr.R.D.Kandou Manado periode tahun 2011-2012

\begin{tabular}{lccc}
\hline \multicolumn{1}{c}{ Regio kepala } & $\mathbf{2 0 1 1}$ & $\mathbf{2 0 1 2}$ & Persentase (\%) \\
\hline $\begin{array}{l}\text { Regio Frontalis } \\
\text { Regio orbitalis-Infraorbitalis-Zygomatica- }\end{array}$ & 17 & 14 & $16.50 \%$ \\
$\begin{array}{l}\text { Nasalis } \\
\text { Regio Temporalis }\end{array}$ & 19 & 18 & $9.04 \%$ \\
$\begin{array}{l}\text { Regio Oralis-Mentalis-Bucalis- } \\
\text { Paratideomassetica }\end{array}$ & 9 & 6 & $19.68 \%$ \\
Regio Parietalis & 19 & 12 & $7.97 \%$ \\
Regio Occipitalis & 12 & 10 & $16.50 \%$ \\
Bukan Cedera Kepala & 26 & 9 & $11.70 \%$ \\
Jumlah & 110 & 78 & $19.00 \%$ \\
\hline
\end{tabular}


Tabel 4. Jumlah korban meninggal akibat kecelakaan lalu lintas berdasarkan jenis kelamin yang masuk di bagian

Forensik BLU RSUP Prof.Dr.R.D.Kandou Manado periode tahun2011-2012

\begin{tabular}{lcc}
\hline Tahun & Laki-laki & Perempuan \\
\hline 2011 & 96 & 14 \\
2012 & 59 & 19 \\
Persentase (\%) & $82.40 \%$ & $17.60 \%$ \\
\hline
\end{tabular}

Tabel 5. Jumlah korban meninggal akibat kecelakaan lalu lintas berdasarkan umur yang masuk di bagian Forensik

BLU RSUP Prof.Dr.R.D.Kandou.Manado periode tahun 2011-2012

\begin{tabular}{lcc}
\hline Umur (Tahun) & Jumlah Korban & Persentase (\%) \\
\hline 0 - 2 tahun & 1 & $0.50 \%$ \\
3 - 12 tahun & 4 & $2.10 \%$ \\
$13-19$ tahun & 38 & $20.30 \%$ \\
20 - 40 tahun & 81 & $43.10 \%$ \\
$41-60$ tahun & 45 & $23.90 \%$ \\
$>60$ tahun & 13 & $6.90 \%$ \\
Tanpa Keterangan & 6 & $3.20 \%$ \\
Jumlah & 188 & $100 \%$ \\
\hline
\end{tabular}

Tabel 6. Jumlah korban akibat kecelakaan lalu lintas periode tahun 2011-2012 berdasarkan tingkat pendidikan

\begin{tabular}{cccccc}
\hline \multirow{2}{*}{ Tahun } & \multicolumn{5}{c}{ Tingkat Pendidikan } \\
\cline { 2 - 6 } & SD & SMP & SMA & PT & Tanpa Keterangan \\
\hline 2011 & 2 & 10 & 23 & 71 & 5 \\
2012 & 2 & 9 & 18 & 46 & 2 \\
Jumlah & 4 & 19 & 41 & 117 & 7 \\
\hline
\end{tabular}

Tabel 7. Jumlah korban meninggal akibat kecelakaan lalu lintas berdasarkan peran korban semula dalam berlalu lintas sesuai data di bagian Forensik BLU RSUP.Prof.Dr.R.D.Kandou Manado Periode tahun 2011-2012

\begin{tabular}{|c|c|c|c|c|}
\hline \multirow[b]{2}{*}{ Tahun } & \multicolumn{4}{|c|}{ Peran korban semula } \\
\hline & $\begin{array}{c}\text { Pengemudi/pengendara } \\
\text { sepeda motor }\end{array}$ & $\begin{array}{c}\text { Yang } \\
\text { dibonceng } \\
\text { sepeda motor }\end{array}$ & $\begin{array}{c}\text { Penumpang } \\
\text { mobil }\end{array}$ & Pejalan kaki \\
\hline 2011 & 72 & 24 & 7 & 7 \\
\hline 2012 & 48 & 14 & 12 & 4 \\
\hline Jumlah & 120 & 38 & 19 & 11 \\
\hline
\end{tabular}




\section{PEMBAHASAN}

Tabel 1.

Tabel ini menggambarkan seluruh jumlah kasus kematian akibat kecelakaan di kota Manado menurut data di bagian Forensik BLU RSUP Prof.Dr.R.D.Kandou.Manado Data yang diperoleh di bagian Forensik BLU RSUP Prof.Dr.R.D.Kandou.Manado adalah sebagai berikut:

a. Pada tahun 2011 terdapat 110 kasus dengan 87 kasus di periksa, dan adapun 23 kasus yang tidak diperiksa.

b. Pada tahun 2012 terdapat 78 kasus dengan 71 kasus di periksa, dan adapun 7 kasus yang tidak diperiksa.

Pemeriksaan medik ini dilakukan untuk membantu penegakan hukum antara lain adalah pembuatan visium et repertum terhadap seseorang yang dikirim oleh penyidik karena diduga sebagai korban tindak pidana. Adapun tujuan dilakukan visium et repertum yaitu menentukan identitas korban, menentukan sebab dari kematian, menentukan pola cedera, menentukan ada tidaknya penyakit alamiah, pengaruh obat atau alkohol, dan membuat kesimpulan dari hasil pemeriksaan

\section{Tabel 2}

Tabel ini menggambarkan angka kecelakaaan lalu lintas yang meninggal dengan cedera kepala di Manado menurut data di bagian Forensik BLU RSUP Prof.Dr.R.D.Kandou Manado periode tahun 2011-2012

a. Pada tahun 2011 terdapat 87 kasus kecelakaan yang diperiksa dan 23 kasus yang tidak di periksa, dari 87 kasus yang di periksa ditemukan 84 cedera kepala. Terdapat juga 26 kasus bukan cedera kepala yang terdiri dari 23 kasus yang tidak di periksa dan 3 kasus yang telah di periksa didapati bukan cedera kepala.

b. Pada tahun 2012 terdapat 71 kasus kecelakaan yang diperiksa dan 7 kasus yang tidak di periksa, dari 71 kasus yang di periksa ditemukan 69 cedera kepala. Terdapat juga 9 kasus bukan cedera kepala yang terdiri dari 7 kasus yang tidak di periksa dan 2 kasus yang telah di periksa didapati bukan cedera kepala

Dari data diatas dapat diambil kesimpulan kalau pola kecelakaan lalu lintas yang paling banyak terjadi adalah cedera kepala

\section{Tabel 3}

Tabel ini menggambarkan kasus kecelakaan yang meninggal dengan cedera kepala sesuai regio kepala yang mengalami cedera pada data di bagian Forensik BLU RSUP Prof.Dr.R.D.Kandou.Manado periode tahun 2011-2012.

Data yang diperoleh di bagian Forensik BLU RSUP Prof.Dr.R.D.Kandou.Manado adalah sebagai berikut:

a. Pada tahun 2011 dan 2012 dari 188 kasus korban kecelakaan lalu lintas paling banyak mengalami cedera kepala diregio temporalis dengan persentase $19.68 \%$, diikuti regio frontalis dan regio parietalis dengan persentase $16.50 \%$, diikuti regio occipitalis dengan persentase $11.70 \%$, dan regio orbitalis-infraorbitalis-zygomatica-nasalis ditemukan dengan persentase 9.04\%, serta regio oralis-mentalis-bucalisparatideomassetica persentasenya adalah $7.97 \%$.

b. Di tahun 2011 dan 2012 juga ditemukan 18.61\% kasus kecelakaan lalu lintas bukan cedera kepala yang terdiri dari kasus kecelakaan lalu lintas yang tidak di periksa dan kasus kecelakaan lalu lintas yang telah di periksa namun bukan cedera kepala. 


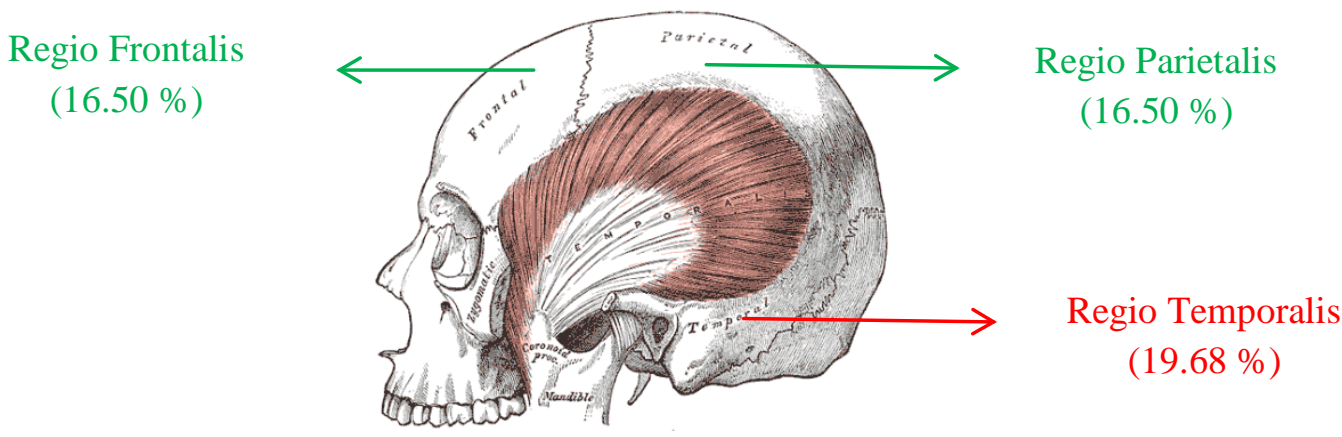

Gambar 2.Regio-regio kepala.Terlihat pembagian-pembagian regio kepala, dimana tiga regio kepala terbesar terdiri dari regio frontalis, regio parietalis, dan regio temporalis.Berdasarkan hasil penelitian yang telah dilakukan di bagian Forensik BLU RSUP Prof.Dr.R.D.Kandou.Manado terdapat $19.68 \%$ regio temporalis dimana hasil ini merupakan hasil terbanyak dibandingkan dengan regio kepala lainnya. Sumber: http://upload.wikimedia.org/wikipedia/commons/d/d3/Gray382.png

Regio temporalis adalah regio yang paling rentan mengalami cedera kepala pada pengendara sepeda motor. Jika regio temporalis ini mengalami cedera, akan terjadi terpisahnya lapisan periosteum durameter dengan tabula interna tulang tengkorak atau yang sering disebut perdarahan epidural, dimana sumber perdarahan paling sering adalah robekan arteri-arteri meningea seperti arteri meningea media. ${ }^{14}$

\section{Tabel 4}

Tabel ini menggambarkan korban meninggal yang masuk di bagian Forensik BLU RSUP Prof.Dr.R.D.Kandou Manado periode tahun 2011-2012 berdasarkan jenis kelamin.

Data dari tabel tersebut dapat disimpulkan bahwa korban paling banyak meninggal dengan cedera kepala pada kecelakaan lalu lintas adalah laki-laki sebanyak 82.4\%.

Korban meninggal dengan cedera kepala pada kecelakaan lalu lintas paling banyak adalah laki-laki, dikarenakan populasi laki-laki lebih besar dari pada perempuan, dan untuk laki-laki dewasa dituntut untuk bekerja keras mencari nafkah di luar tempat tinggal, sehingga laki-laki merupakan objek terbanyak dalam menggunakan jalan raya khususnya dalam berlalu lintas.

Tabel 5

Tabel ini menggambarkan korban meninggal yang masuk di bagian Forensik BLU RSUP Prof.Dr.R.D.Kandou Manado periode tahun 2011-2012 berdasarkan umur.

Data dari tabel tersebut dapat disimpulkan bahwa korban paling banyak meninggal dengan cedera kepala pada kecelakaan lalu lintas adalah usia 20-40 tahun sebanyak 43.10\%. Hal ini sangat memprihatinkan karena dalam rentang usia ini merupakan usia reproduktif, dimana kebanyakan pada rentang umur ini ada yang masih bersekolah untuk menata masa depan atau usia yang masih tergolong muda.

\section{Tabel 6}

Tabel ini menggambarkan korban meninggal yang masuk di bagian Forensik BLU RSUP Prof.Dr.R.D.Kandou Manado periode tahun 2011-2012 berdasarkan tingkat pendidikan.

Data dari tabel tersebut dapat disimpulkan bahwa paling banyak korban mengalami kecelakaan lalu lintas adalah mahasiswa perguruan tinggi. Hal ini dikerenakan masa perguruan tinggi merupakan masa dimana dalam pencarian jati diri sehingga cenderung memiliki emosi labil dan mudah masuk dalam pergaulan lebih besar dan bebas sehingga mudah terpengaruh dengan pergaulan geng motor ataupun geng mobil yang kadang kurang menaati peraturan lalu lintas untuk melakukan kebut-kebutan di jalan raya. 


\section{Tabel 7}

Tabel ini menggambarkan korban meninggal yang masuk di bagian Forensik BLU RSUP Prof.Dr.R.D.Kandou Manado periode tahun 2011-2012 berdasarkan peran korban semula dalam berlalu lintas.

Data dari tabel diatas dapat disimpulkan peran sebagai pengemudi/pengendara merupakan paling banyak menjadi korban cedera kepala pada kecelakaan lalu lintas, tercatat sebanyak 120 kasus dari 188 kasus meninggal dengan cedera kepala pada kecelakaan lalu lintas, hal ini tejadi baik tidak memakai helm maupun memakai helm tapi bukan helm standart, tidak memakai sabuk pengaman, dan tidak mematuhi peraturan dalam berlalu lintas.

\section{PENUTUP}

\section{Kesimpulan}

Jadi dari hasil penelitian mengenai gambaran korban meninggal dengan cedera kepala pada kecelakaan lalu lintas di bagian Forensik BLU RSUP Prof.Dr.R.D.Kandou Manado periode tahun 2011-2012 diperoleh kesimpulan sebagai berikut:

1. Selama periode tahun 2011-2012, korban meninggal karena kecelakaan lalu lintas sebagian besar dilakukan pemeriksaan, sehingga dapat diketahui daerah tubuh mana yang mengalami cedera yang dapat mengakibatkan kematian.

2. Terjadi penurunan kecelakaan lalu lintas yang signifikan dari tahun 2011 ke tahun 2012 .

3. Pola cedera yang paling banyak ditemukan pada korban kecelakaan adalah cedera kepala.

4. Sesuai dengan regio kepala yang ada di tabel 3, ditemukan regio temporalis merupakan regio yang paling banyak terjadi cedera.

5. Korban kecelakaan lalu lintas dengan cedera kepala paling banyak adalah jenis kelamin laki-laki yaitu $82.4 \%$.

6. Korban paling banyak meninggal dengan cedera kepala pada kecelakaan lalu lintas adalah usia 20-40 tahun sebanyak 43.10\%

7. Korban kecelakaan lalu lintas dengan cedera kepala paling banyak terjadi pada perguruan tinggi.

8. Peran korban semula dalam berlalu lintas paling banyak yang mengalami cedera kepala pada kecelakaan lalu lintas adalah sebagai pengemudi/ pengendara sedangkan yang paling sedikit adalah pejalan kaki.

\section{Saran}

1. Mengingat pentingnya keselamatan dalam berlalu lintas agar tidak terjadinya kecelakaan lalu lintas perlu dikembangkan lagi pengetahuan tentang peraturan rambu-rambu lalu lintas, seperti penggunaan helm yang benar, penggunaan sabuk pengaman saat mengemudi, serta mengontrol kecepatan saat mengemudi dan mengendara sepeda motor di tengah kota. Yang terutama harus diketahui dan dimengerti oleh para pengendara kendaraan bermotor khususnya sepeda motor yaitu penggunaan helm sesuai standart yang telah ditetapkan. Hal ini dapat diterapkan dengan penyuluhan dari para medis dan kepolisian.

2. Diharapkan juga pihak kepolisian lebih tertib lagi dalam pemberian Surat Izin Mengemudi pada orang yang tepat dan sesuai persyaratan yang telah ada, pengawasan penggunaan sabuk pengaman dan penggunaan helm lebih ditingkatkan serta harus diberi sanksi yang tegas jika melanggar peraturan. 
3. Bagi pemerintah hendaknya juga, dapat lebih meningkatkan pencegahan dengan memperhatikan keadaan jalan raya yang sudah tidak layak digunakan, agar dapat dilakukan perbaikan jalan maupun pelebaran jalan yang sempit.

4. Menimbang korban meninggal yang masuk di bagian Forensik BLU RSUP Prof.Dr.R.D.Kandou Manado paling banyak adalah korban kecelakaan lalu lintas perlu dilakukan autopsi, untuk menemukan penyebab pasti dan untuk kepentingan peradilan. Saat hal ini dilakukan dapat juga berguna bagi para dokter muda yang melakukan kepanitraan klinik di bagian Forensik dalam upaya melatih ketrampilan.

5. Untuk orang tua diharapkan tetap melakukan pengawasan yang ketat bagi anak-anak agar anak-anak dibawah umur tidak mengendarai kendaraan bermotor serta tetap melakukan pengawasan terhadap pendidikan dan lingkungan pergaulan anak.

\section{DAFTAR PUSTAKA}

1. Riyadina W, Subik IP. Profil Keparahan pada Korban Kecelakaan Sepeda Motor di Instalasi Gawat Darurat RSUP Fatmawati: [Skripsi]. Jakarta: UNIV-MEDICINE;2007.

2. Banga YT. Gambaran Korban Meninggal Akibat Kecelakaan Lalu Lintas di Manado yang Masuk dibagian Forensik BLU RSUP Prof.Dr.R.D.Kandou Manado Periode January 2008-Desember 2010. [Skripsi]. Manado:FK-UNSRAT;2011.

3. Jumlah Kecelakaan, Korban Mati, Luka Berat, Luka Ringan dan Kerugian Materi yang Diderita Tahun 1992-2011 [homepage on the internet]. Available from: http//www.bps.go.id/tab_sub/print.php?id_subjek=17\&notab=14

4. Fitriah WW, Masruni M, Irhamah. Faktor-faktor yang Mempengaruhi Keparahan Korban Kecelakaan Lalu Lintas dikota Surabaya dengan Pendekatan Begging Regresi Logistik Ordinal [homepage on the internet]. Available from: http://ejurnal.its.ac.id/index.php.sains_seni/article/download/2029

5. Cause of head injury [homepage on the internet]. Available from: www.medicinenet.com/head_injury/article.htm

6. Facs TGS.Management of Head Injury.American Association of Neurogical Surgeons and Congress of Neurological Surgeons, 1998

7. Advanced Trauma Life Support For doctors. American Collage of Surgeons Committee On Trauma. 2004.

8. Antou SW. Manfaat Helm Dalam Mencegah Kematian Akibat Cedera Kepala Pada Kecelakaan Lalu Lintas. [Skripsi]. Manado:FK-UNSRAT;2013. 